\title{
Concrete bridge deck slabs strengthened with UHPFRC
}

\author{
Maléna BASTIEN- \\ MASSE \\ M.A.Sc., Civil Engineer \\ École Polytechnique \\ Fédérale de Lausanne \\ (EPFL), Switzerland \\ malena.bastien-masse@epfl.ch
}

Maléna Bastien Masse, born in 1985, received her degree and master in civil engineering from Ecole Polytechnique de Montreal in Canada. She is now working towards a doctoral degree in structural engineering in EPFL, Switzerland.

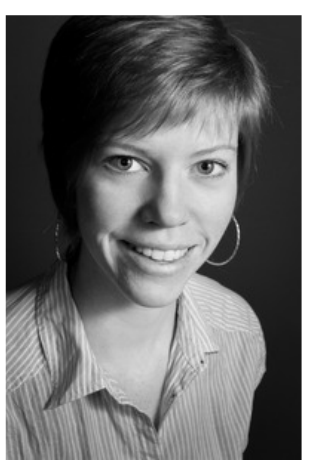

\author{
Eugen BRÜHWILER \\ Professor, Dr. Civil \\ Engineer ETH \\ École Polytechnique \\ Fédérale de Lausanne \\ (EPFL), Switzerland \\ eugen.bruehwiler@epfl.ch
}

Eugen Brühwiler, born in 1958, received his civil engineering and doctoral degrees from the Swiss Federal Institutes of Technology in Zurich and Lausanne. His research interests include examination of structural safety

and UHPFRC for strengthening
and rehabilitation of structures.

and UHPFRC for strengthening
and rehabilitation of structures.

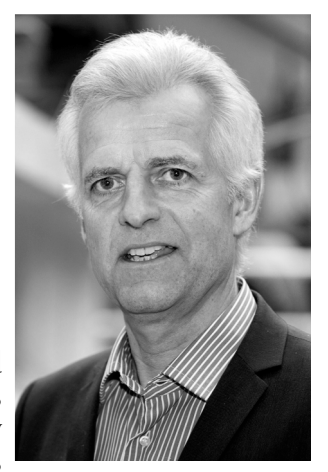

\section{Summary}

An original concept is presented for the durable rehabilitation of concrete bridge deck slabs. The main idea is to add a layer of Ultra-High Performance Fiber Reinforced Concrete (UHPFRC) with steel reinforcing bars over the concrete slab to create a composite section. The layer of UHPFRC is waterproof and protects the reinforced concrete against severe environmental influences. It also strengthens the structural element for high traffic loads. Experimental studies on composite beams in a cantilever setup were carried out to identify the different failure modes and the contribution of the UHPFRC layer to the resistance. Analytical models were then developed to calculate the resistance of composite beams. The concept has been validated by field applications demonstrating that the technology of UHPFRC is mature for cast in-situ.

Keywords: UHPFRC, composite section, reinforced concrete, resistance, failure mode, analytical model, rehabilitation, strengthening.

\section{Introduction}

Rehabilitation of deteriorated concrete structures is a heavy burden from the socio-economic viewpoint since it leads to significant user costs. As a consequence, novel concepts for the rehabilitation of those structures must be developed. To increase the life span of a reinforced concrete bridge deck slab, it is possible to add a layer of 30 to $60 \mathrm{~mm}$ of Ultra-High Performance Fiber Reinforced Concrete (UHPFRC) with or without small diameter steel reinforcement bars, thus creating a composite section (Fig. 1).

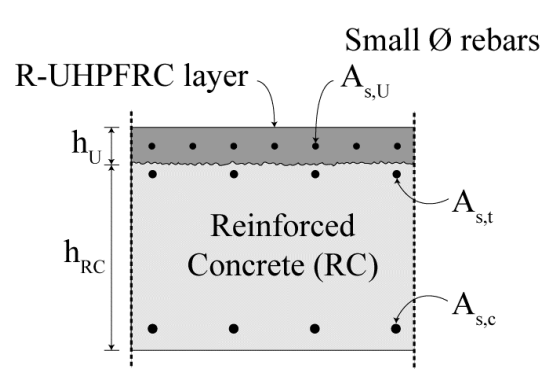

Fig. 1: Typical composite section [3]
UHPFRC is a cementitious composite material known for its excellent properties: extremely low permeability which prevents the ingress of detrimental substances such as water and chlorides [1] and very high strength, i.e., compressive strength higher than $150 \mathrm{MPa}$, tensile strength higher than $10 \mathrm{MPa}$ and with considerable tensile strain hardening and softening behaviour [2]. A UHPFRC layer can thus be used to protect the concrete slab against severe environmental influences and to strengthen it for high traffic loads as proposed in [3]. In this paper the layer of UHPFRC is considered as a tensile reinforcement for the reinforced concrete $(\mathrm{RC})$ section 
The original conceptual idea (developed in 1999) has been investigated by means of extensive research aimed at characterizing UHPFRC as well as the structural behaviour of R-UHPFRC - RC composite structural members, combining material and structural engineering sciences. This paper presents the tensile behaviour of UHPFRC followed by the results of a large experimental study on a series of composite beams tested in a cantilever test setup. Using the test results, analytical models to predict the failure mode and resistance of the composite beams are developed. To conclude a field application on a bridge in Switzerland is described.

\section{UHPFRC in tension}

As illustrated in Fig. 2, the uniaxial tensile behaviour of UHPFRC is divided into three phases. First, the material is elastic up to initiation of microcracking of the matrix. The elastic limit strength $f_{U t, e l}$ has typical values of 7 to $11 \mathrm{MPa}$ for currently used UHPFRCs.

Second, it goes into a phase of strain hardening with multiple (non-visible) microcracking of the
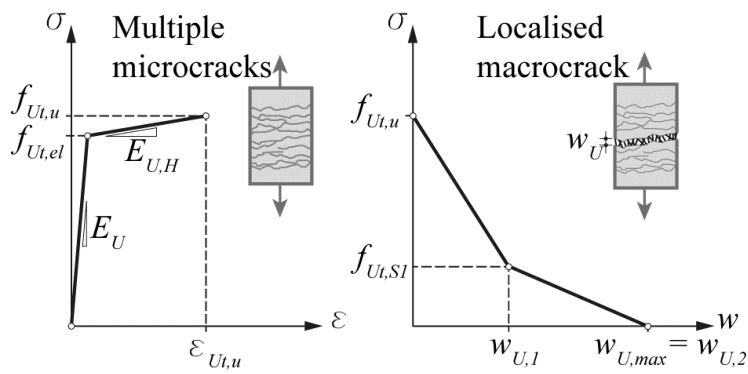
matrix and fiber activation. The material still behaves like a continuum. Strain hardening domain may reach strains of 2 to $5 \%$ where the tensile strength $f_{U t, u}$ is reached with typical values ranging from 9 to $15 \mathrm{MPa}$.

Third, upon the formation of a discrete macrocrack at ultimate resistance, the phase of strain softening begins and the behaviour of the

Fig. 2: Tensile behaviour of plain material is described by a stress-crack opening law

UHPFRC [3] with maximum crack openings reaching about half of the fiber length, i.e., 5 to $8 \mathrm{~mm}$.

\section{Experimental investigation on composite beams}

Flexural tests on composite beams showed that the layer of R-UHPFRC, when used as a tensile reinforcement, increases the resistance up to $165 \%$ compared to a reference $\mathrm{RC}$ beam [4]. A flexural failure happens along a vertical crack where the highest moment is applied. A macrocrack appears in the RC section while distributed microcracks develop in the UHPFRC layer. In the postpeak domain, fracture of R-UHPFRC occurs in the section with the localization of a macrocrack. No debonding is observed at the interface between the UHPFRC layer and the concrete prior to failure [3]. It is thus supposed that the behavior of composite beams is monolithic when submitted to pure flexural moments.

To study the behavior of composite beams submitted to combined bending and shear, an extensive experimental campaign was carried out. Composite beams were tested in a cantilever test setup. The main goal of these tests is to study the different failure modes and mechanisms of composite beams and the contribution of the UHPFRC layer to shear resistance. Important results of this campaign are presented hereafter.

\subsection{Specimens}

Two types of specimens were tested. The beams of the B series were tested by Noshiravani [6]. As shown in Fig. 3. (a), they have a width of $150 \mathrm{~mm}$ and a total height of $300 \mathrm{~mm}$. They are similar to slab ribs with stirrups spaced at $400 \mathrm{~mm}$. The beams of the S series (Fig. 3 (b)) are wider with a width of $400 \mathrm{~mm}$ and a total height of $220 \mathrm{~mm}$. These specimens are closer to slab strips because they have no shear reinforcement. For both cases, the layer of UHPFRC has a height of $50 \mathrm{~mm}$. 
(a)

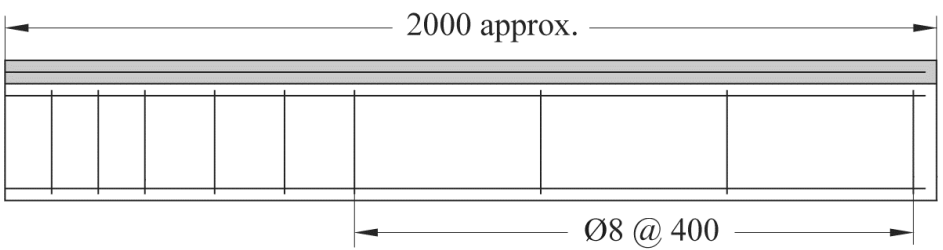

(b)

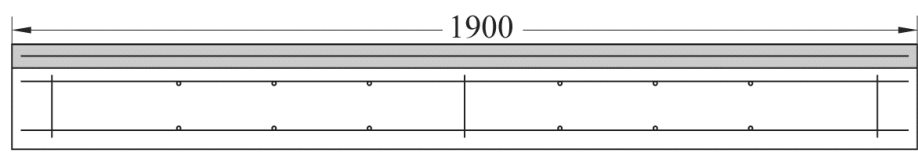

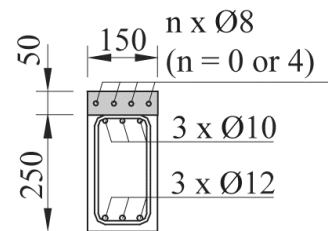

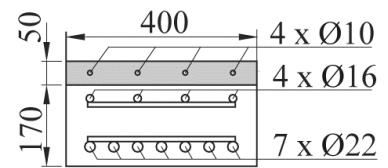

$[\mathrm{mm}]$

Fig. 3: Geometry of specimens (a) B series [6]; (b) S series

\subsection{Material properties}

Table 1: Concrete and UHPFRC properties

\begin{tabular}{ccc||ccccc}
\multicolumn{3}{c||}{ Concrete } & \multicolumn{5}{c}{ HIFCOM 13 } \\
\cline { 2 - 7 } Series & $\begin{array}{c}\mathbf{E}_{\mathbf{c}} \\
{[\mathbf{G P a}]}\end{array}$ & $\begin{array}{c}\boldsymbol{f}_{\boldsymbol{c}} \\
{[\mathbf{M P a}]}\end{array}$ & $\begin{array}{c}\mathbf{E}_{\mathbf{c}} \\
{[\mathbf{G P a}]}\end{array}$ & $\begin{array}{c}\boldsymbol{f}_{\boldsymbol{c}} \\
{[\mathbf{M P a}]}\end{array}$ & $\begin{array}{c}\boldsymbol{f}_{\boldsymbol{u} t, \boldsymbol{e l}} \\
{[\mathbf{M P a}]}\end{array}$ & $\begin{array}{c}\boldsymbol{\varepsilon}_{\boldsymbol{u t}, \boldsymbol{u}} \\
{\left[\mathbf{\%}_{\mathbf{o}}\right]}\end{array}$ & $\begin{array}{c}\boldsymbol{f}_{\boldsymbol{u t}, \boldsymbol{u}} \\
{[\mathbf{M P a}]}\end{array}$ \\
\hline B [4] & 29,9 & 41,6 & 48,8 & 160 & 10 & 3,0 & 12 \\
$\mathrm{~S}$ & 31,4 & 56,8 & 43,8 & 227 & 10 & 3,0 & 12 \\
\hline
\end{tabular}

Table 2: Steel properties

Fig. 4: Cantilever test setup
All RC substrates were fabricated with a normal strength concrete and a maximum aggregate size of $16 \mathrm{~mm}$. The layer of UHPFRC is cast with an in-house mix called HIFCOM 13 [4]. Table 1 gives the average values of the

\begin{tabular}{|c|c|c|c|c|}
\hline \multicolumn{4}{|c|}{ Table 2: Steel properties } & concrete an \\
\hline $\begin{array}{c}\emptyset \\
{[\mathbf{m m}]}\end{array}$ & $\begin{array}{c}f_{s y} \\
\text { [MPa] }\end{array}$ & $\begin{array}{c}\varepsilon_{s u} \\
{\left[\%_{0}\right]}\end{array}$ & $\begin{array}{c}f_{s u} \\
\text { [MPa] }\end{array}$ & \multirow{2}{*}{$\begin{array}{l}\text { The steel use } \\
\text { nominal yielc } \\
\text { values obtain }\end{array}$} \\
\hline 8 & 516 & 4,9 & 589 & \\
\hline 10 & 594 & 4,3 & 653 & \\
\hline 12 & 571 & 5,0 & 640 & All snecci \\
\hline $\begin{array}{l}14 \text { and } \\
\text { more }\end{array}$ & 565 & 9,8 & 663 & $\begin{array}{l}\text { Fig. 4. The } \\
\text { The length }\end{array}$ \\
\hline Pin & $\begin{array}{l}\text { A-A } \\
F^{-0}\end{array}$ & - pres & & $\mathbf{\pm}^{\mathrm{P}}$ \\
\hline
\end{tabular}

the mechanical reinforcement ratio $\omega_{i}$. In this case, the subscript $i$ stands for the tensile longitudinal the mechanical reinforcement ratio $\omega_{i}$. In this case, the subscript $i$ stands for the tensile longitudinal reinforcement which are UHPFRC $(U)$ or tensile rebars in R-UHPFRC $(s, U)$ or RC section $(s, t)$. Equations 1 and 2 calculate $d$ and $\omega_{i}$ where $d_{i}$ is the static height of the considered reinforcement, $A_{i}$ is the area and $f_{i}$ is the tensile strength.

$$
\begin{aligned}
& d=\frac{\sum d_{i} A_{i} f_{i}}{\sum A_{i} f_{i}} \\
& \omega_{i}=\frac{A_{i} f_{i}}{A_{c} f_{c}}
\end{aligned}
$$


Table 3: Test parameters

\begin{tabular}{|c|c|c|c|c|c|c|c|c|c|c|}
\hline $\begin{array}{c}\text { Serie } \\
\mathbf{s}\end{array}$ & $\begin{array}{c}\mathbf{b} \\
{[\mathrm{mm}]}\end{array}$ & $\begin{array}{c}\mathbf{h} \\
{[\mathrm{mm}]}\end{array}$ & Beam & $\underset{[\mathrm{mm}]}{a}$ & $\stackrel{l}{l}$ & $a / d$ & $\begin{array}{c}\rho_{s v} \\
{[\%]}\end{array}$ & $\begin{array}{c}\omega_{\mathrm{s}, t} \\
{[\%]}\end{array}$ & $\begin{array}{c}\omega_{U} \\
{[\%]}\end{array}$ & $\begin{array}{l}\omega_{\mathrm{s}, U} \\
{[\%]}\end{array}$ \\
\hline \multirow{3}{*}{$B$ [6] } & \multirow{3}{*}{150} & \multirow{3}{*}{300} & B_MW0 & 800 & 1600 & 3,4 & 0,17 & 8,1 & 0 & 0 \\
\hline & & & B_MW1 & 800 & 1600 & 3,2 & 0,17 & 8,1 & 3,9 & 0 \\
\hline & & & B_MW4 & 800 & 1600 & 3,1 & 0,17 & 8,1 & 3,9 & 7,3 \\
\hline \multirow{3}{*}{$\mathbf{S}$} & \multirow{3}{*}{400} & \multirow{3}{*}{220} & S_L1 & 1000 & 1500 & 6,0 & 0 & 12,3 & 6,2 & 4,8 \\
\hline & & & $\mathrm{S}^{-} \mathrm{M} 1$ & 700 & 1500 & 4,2 & 0 & 12,3 & 6,2 & 4,8 \\
\hline & & & S_S1 & 450 & 1500 & 2,7 & 0 & 12,3 & 6,2 & 4,8 \\
\hline
\end{tabular}

The tests are displacement controlled. The displacement is applied with a hydraulic jack and a load cell measures the force, while a linear vertical displacement transducer measures the displacement.

\subsection{Test results}

\subsubsection{B series [6]}

To show the contribution of the layer of UHPFRC to the failure mechanisms and resistance of a composite beam, the results of tests conducted on three specimens of the B series are presented hereafter. Each specimen has a different amount of tensile reinforcement. Beam MW0 is a reinforced concrete beam with no UHPFRC layer. Beam MW1 has a plain layer of UHPFRC and beam MW4 has a layer of R-UHPFRC. All the beams have a shear span of $800 \mathrm{~mm}$.

Fig. 5 presents the test results for those three specimens. The RC beam, MW0, failed in flexureshear. A flexure-shear failure occurs when a flexural vertical crack rotates towards the roller support and develops diagonally. At maximum force, sudden decrease of resistance was observed followed by some deformation capacity on a rather constant force level. Fracture finally was due to the crushing of the concrete near the support at the crack tip.

(a)

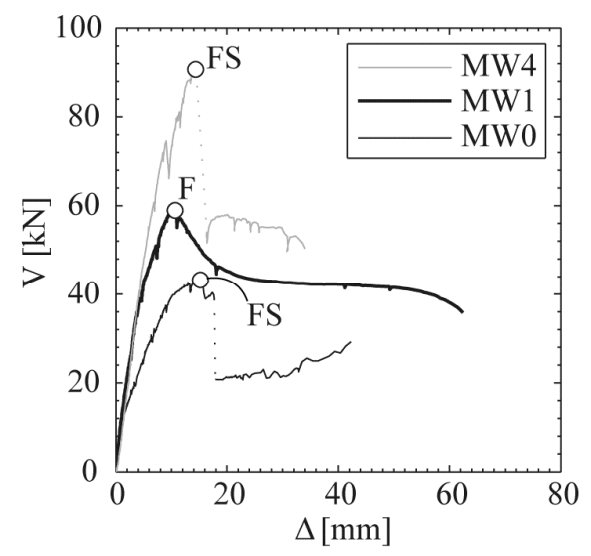

(b)

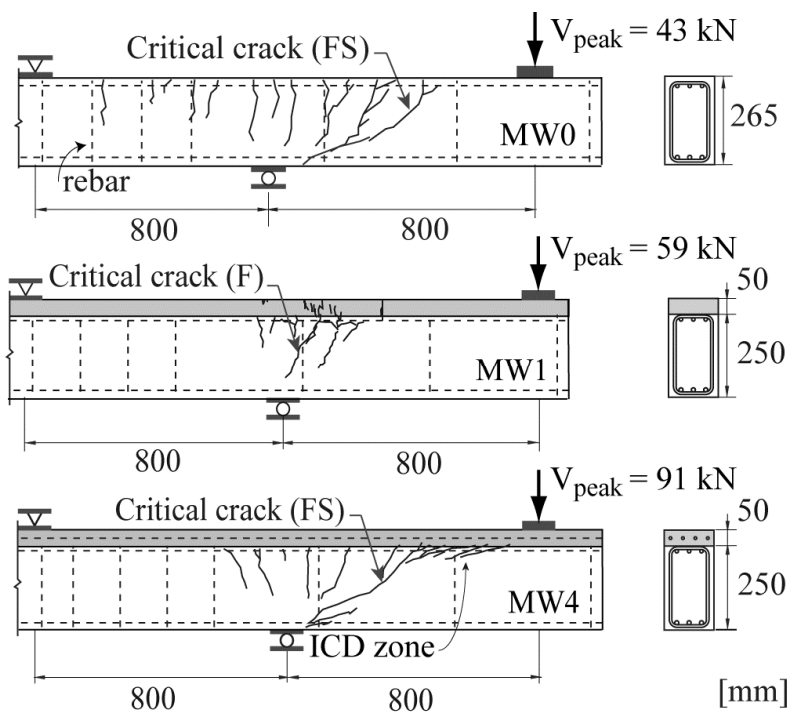

Fig. 5: Tests results for B series [6]: (a) Force-deflection responses; (b) crack patterns at peak load

By adding a layer of plain UHPFRC over the RC section (beam MW1), no sudden decrease of resistance after peak occurred and the resistance is increased. Beam MW1 showed a flexural failure along a vertical crack over the support. After a ductile flexural failure, the element retains a significant proportion of its resistance and rotation capacity. In the case of beam MW4, reinforcement was added in the UHPFRC layer. The resistance of the element was once more significantly increased. The beam failed in flexure-shear, showing relatively small deformations. This demonstrates that it is possible to over-strengthen a beam in bending thus leading to a flexure- 
shear failure. The cracking pattern of beam MW4 gives interesting information on the shear resisting mechanisms of a composite beam. During the test the widening of the inclined crack caused a softening of the concrete below the UHPFRC layer. This debonding occurs between the mouth of the inclined crack and the load point. It is due to the opening of a diagonal crack and is known as Intermediate-Crack induced Debonding (ICD) [6].

\subsection{2 $\mathrm{S}$ series}

The results of the tests carried out on the beams of the $\mathrm{S}$ series are presented in Fig. 6 . The three specimens were identical with varying shear span: 1000, 700 and $450 \mathrm{~mm}$. In all cases final failure was flexural along a vertical collapse crack over the roller support. The sudden decrease in resistance visible in the force-deflection diagrams for every beam is due to the rupture of the reinforcing bars in the UHPFRC layer. This always happens in the post-peak domain.

(a)
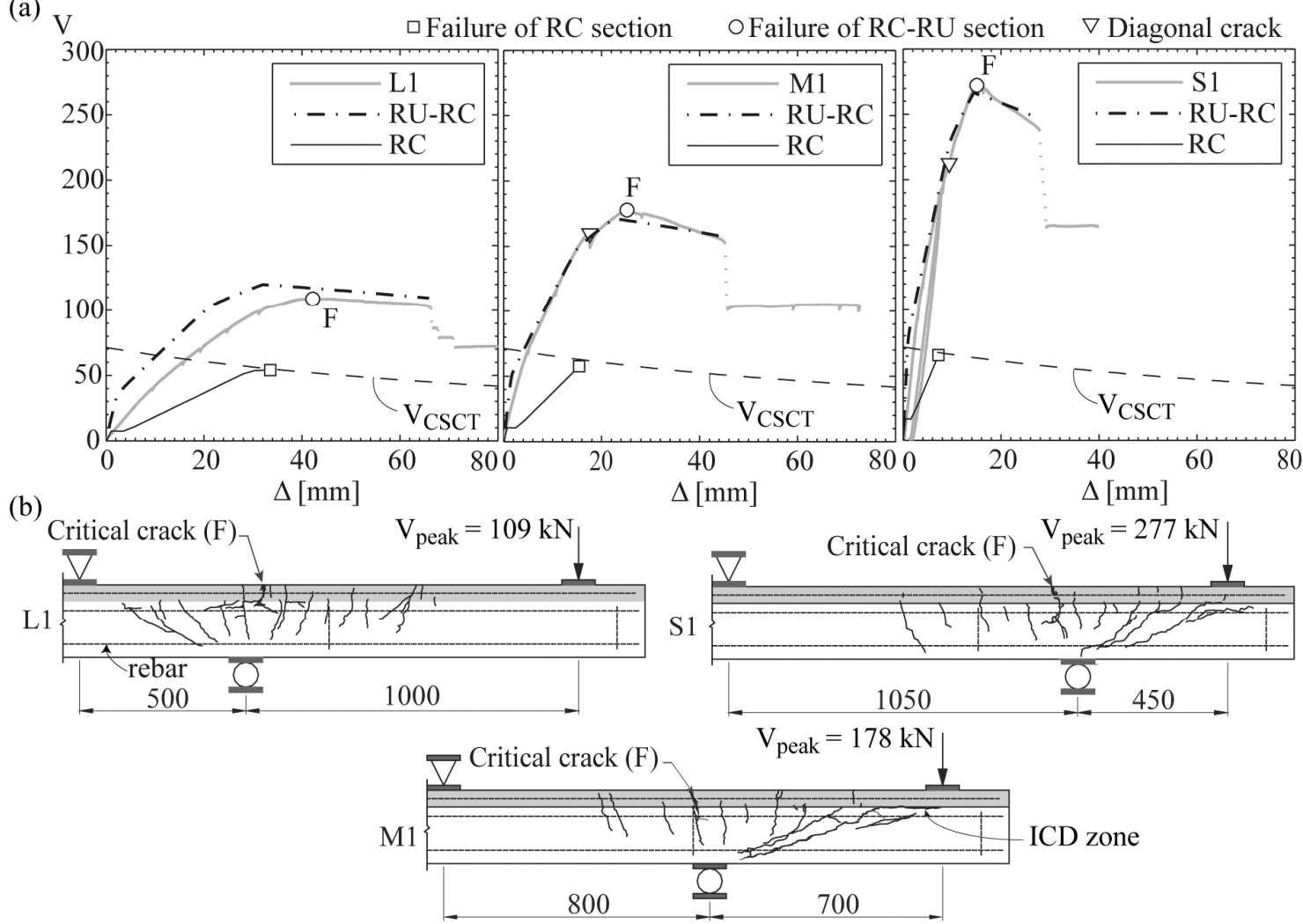

Fig. 6: Tests results for S series: (a) Force-deflection responses; (b) crack patterns at peak load

The graphs in Fig. 6 also give the force-displacement response of the RC section alone. This was calculated with a plain sectional analysis combined with a shear failure criterion. This criterion is based on the critical shear crack theory (CSCT) [7] and is calculated with equation 3. The CSCT calculates shear resistance of concrete as a function of the opening of a diagonal crack and takes account for aggregate interlock.

$$
\begin{aligned}
& \frac{V_{C S C T}}{b d \sqrt{f_{c}}}=\frac{1}{6} \frac{1}{1+2 \frac{\psi d}{16+d_{g}}} \\
& \psi=\frac{\Delta}{a}
\end{aligned}
$$


In all cases, the RC section would have failed in shear and the layer of R-UHPFRC contributed to prevent shear failure and increase the rotation capacity. In the case of beam L1, no diagonal cracks were observed during the test. A triangle in the force-deflection graphs shows the instant when the diagonal crack appeared for beams M1 and S1. The layer of UHPFRC resisted to the opening of this diagonal crack, forcing the final failure to be flexural.

\section{Analytical model}

\subsection{Behaviour in bending}

As described previously, when a beam fails in bending, no debonding between UHPFRC and concrete occurred. The composite beams thus behaved monolithically and the hypothesis of Bernoulli - plane sections remain plane- is valid. To calculate the moment-curvature response and the ultimate resisting moment in bending for a composite beam, it was thus proposed to use a plane section analysis as given in Fig. 7 [3].

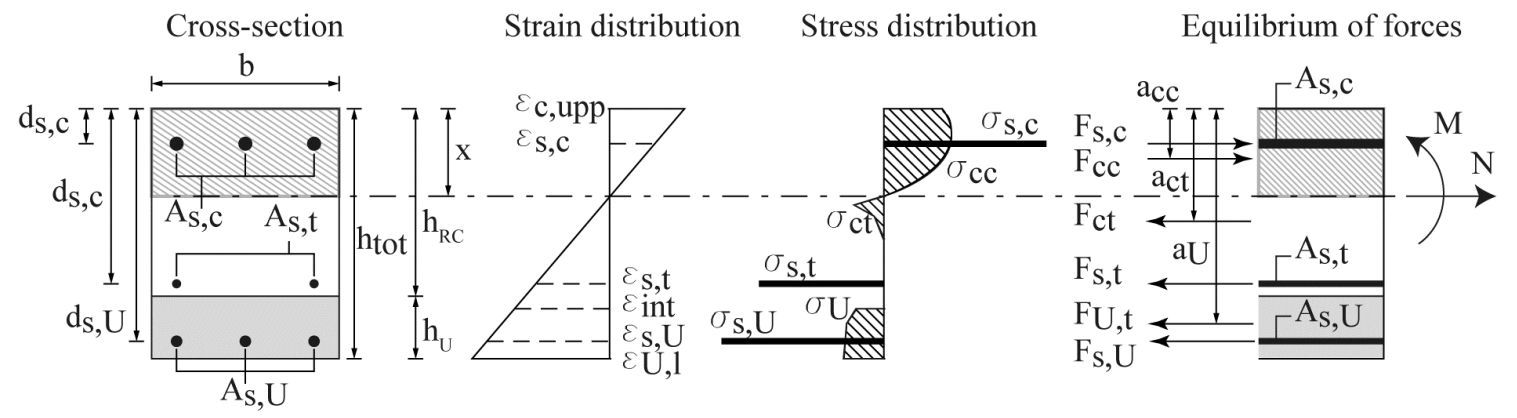

Fig. 7: Definition of the analytical model for bending [3]

For the three beams of the $\mathrm{S}$ series, the force-deflection response was calculated according to this model. The results of these calculations are presented on the graphs of Fig. 6 with the dash-dot line. The model is in good agreement with the experimental results.

\subsection{Behaviour in combined bending and shear}

As illustrated by beam B_MW4, the ICD caused the failure of a composite beam in flexure-shear. Fig. 8 illustrates the mechanism as observed before the collapse. When the diagonal crack widens, it

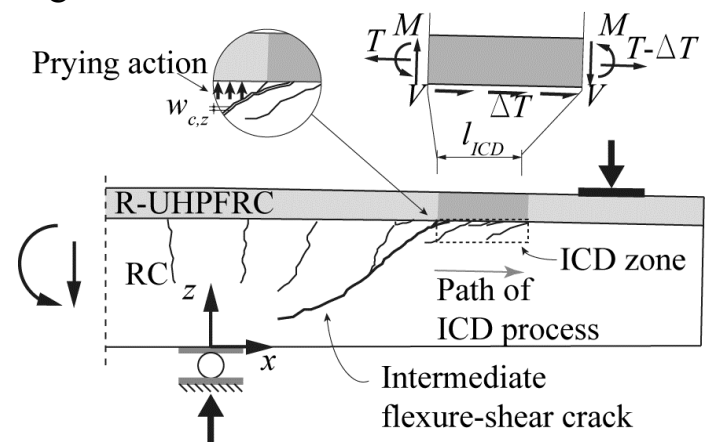

Fig. 8: Intermediate-Crack induced debonding (ICD) [6] creates a prying action on the UHPFRC layer thus creating the softening of the ICD zone and submitting the R-UHPFRC layer to a double curvature [6]. With this debonding, the section can no longer be considered as monolithic and the member stiffness decreases.

This mechanism is used in [6] to propose a simplified formulation to evaluate the flexure-shear strength of a composite beam, $V_{R U-R C}$. Equation 5 calculates it as the sum of the contribution of concrete $\left(V_{C}\right)$, stirrups in steel $\left(V_{S}\right)$ and UHPFRC layer $\left(V_{R U}\right)$.

$$
V_{R U-R C}=V_{c}+V_{S}+V_{R U}
$$

The shear resistance of concrete $V_{C}$ along the diagonal crack is obtained with Equation 6 proposed in [8]. In this equation, $f_{c e}$ is the effective strength of concrete and can be taken as $0,8 f_{c}, \mathrm{c}_{\mathrm{FS}}$ is the height of the neutral axis in the RC section, $\theta_{c}$ is the angle of the diagonal crack in respect to the longitudinal axis while $\alpha$ is the angle of this crack with the vertical axis. 
$V_{c}=\frac{f_{c e} b}{2}\left[\frac{C_{F S}}{\sin \theta_{c}}(1-\sin \propto)\right]$

$V_{s}=A_{v} f_{s y}$

The shear resistance of the UHPFRC layer submitted to bending in double curvature is a function of its flexural resistance $M_{R U, \max }$ and the length of the ICD zone $l_{R U, d l, \max }$, as stated by equation 8 . The bending resistance can be calculated with a plane section analysis while the ICD length is obtained geometrically using the angle of the diagonal crack $\theta_{c}$ and the span length $a$.

$V_{R U}=\frac{2 M_{R U, \max }}{l_{R U, d l, \max }}$

\subsection{Model validation}

Table 4: Model validation

\begin{tabular}{|c|c|c|}
\hline & S_M1 & B_MW4 \\
\hline \multicolumn{3}{|c|}{ Parameters } \\
\hline$C_{F S}[\mathrm{~mm}]$ & 55 & 90 \\
\hline $\boldsymbol{\theta}_{\mathbf{c}}$ & 25 & 30 \\
\hline$\alpha$ & 65 & 60 \\
\hline$M_{R U, \max }[\mathrm{kN} . \mathrm{m}]$ & 8 & 4 \\
\hline$l_{R U, d l, \max }[\mathrm{mm}]$ & 235 & 280 \\
\hline \multicolumn{3}{|c|}{ Strenght } \\
\hline$V_{R, f}[\mathrm{kN}]$ & 171 & 95 \\
\hline$V_{c}[\mathrm{kN}]$ & 111 & 60 \\
\hline$V_{s}[\mathrm{kN}]$ & 0 & 0 \\
\hline$V_{R U}[\mathrm{kN}]$ & 67 & 25 \\
\hline$V_{R, \text { shear }}[\mathrm{kN}]$ & 177 & 86 \\
\hline$V_{\text {peak }}[\mathrm{kN}]$ & 178 & 91 \\
\hline
\end{tabular}

To validate the two models presented in the previous sections, the results of the calculations for two tested beams were compared to the experimental results ( $V_{\text {peak }}$ in Table 4$)$. The two chosen beams are B_MW4 and S_M1. In both cases, an ICD zone was observed during the test (Fig. 6 and 7). For S_M1, the failure was in bending and for B_MW4, it was in flexure-shear. The resisting moment in bending was converted into a force $\left(\mathrm{V}_{\mathrm{R}, \mathrm{f}}\right)$ by dividing it by the shear span $a$.

In Table 4, the value in bold is the minimum between the shear and the flexural strength. It determines the failure mode. The analytical models were able to predict with a good precision the failure mode and the strength of the considered beam (measured experimentally). It is also interesting to notice the little difference between the shear and the bending strength for both cases illustrated here. This shows the importance of a good design for the UHPFRC layer to guarantee ductile behavior of the member.

\section{Application}

A RC massive slab bridge supported by 6 columns, built in 1963 and located near Lausanne, in

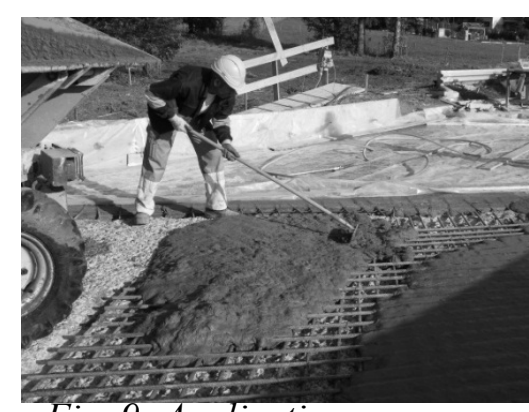

Fig. 9: Application case Switzerland, was reinforced with a layer of UHPFRC (Fig. 9) in autumn 2011 [9]. Before the intervention, the slab parts over the column supports did not meet the requirements for structural safety in bending and shear of the Swiss standards for existing structures [10]. The top layer of approximately 20 to $40 \mathrm{~mm}$ of the $\mathrm{RC}$ slab was first removed with high pressure water jet. Then, a layer of $25 \mathrm{~mm}$ of UHPFRC was cast over the slab for strengthening and waterproofing the slab. Over the column supports, a thicker layer of $65 \mathrm{~mm}$ was placed with $18 \mathrm{~mm}$ diameter steel rebars. This intervention significantly improved the load bearing capacity and durability of the bridge. It also demonstrated the simplicity in applying this technology.

\section{Conclusion}

An experimental campaign on composite elements has demonstrated that a layer of R-UHPFRC over a RC section significantly increases the load bearing capacity and prevents shear failure if 
designed correctly using the proposed analytical models. A site application showed that this concept is also simple to apply to full size structures.

This conceptual idea combines efficiently the protection and resistance properties of UHPFRC with conventional structural concrete. The rehabilitated structures have significantly improved structural resistance and durability. This original concept should also be applied for the construction of durable new reinforced concrete structures [11].

\section{References}

[1] CHARRON J.-P., DÉNARIÉ E., and BRÜHWILER, E. "Permeability of Ultra-High Performance Fiber Reinforced Concretes (UHPFRC) under high stresses", Materials and Structures, Vol. 40, No. 3, 2007, pp. 269-277.

[2] DENARIÉ E., and BRÜHWILER E. "Strain Hardening of Ultra-High Performance Fibre Reinforced Concrete: Deformability versus Strength Optimization”, International Journal for Restoration of Buildings and Monuments, Vol. 12, No. 6, 2011, pp.397-410.

[3] HABEL K. Structural Behaviour of Elements Combining Ultra-High Performance FibreReinforced Concretes and Concrete, Doctoral Thesis, No. 3036, Ecole Polytechnique Fédérale de Lausanne, Switzerland, 2004, p. 195.

[4] OESTERLEE C. Structural Response of Reinforced UHPFRC and RC Composite Members, Doctoral Thesis, No. 4848, Ecole Polytechnique Fédérale de Lausanne, Switzerland, 2010, p. 136.

[5] WUEST J. Comportement structural des bétons de fibres ultra performants en traction dans deséléments composes, Doctoral thesis, No. 3987, Ecole Polytechnique Fédérale de Lausanne, Switzerland, 2007, p. 244.

[6] NOSHIRAVANI T. Structural Response of R-UHPFRC-RC Composite Members Subjected to Combined Bending and Shear, Doctoral Thesis, No. 5246, Ecole Polytechnique Fédérale de Lausanne, Switzerland, 2012, p. 188.

[7] VAZ RODRIGUES R., MUTTONI A. and FERNÁNDEZ RUIZ M, "Influence of Shear on Rotation Capacity of Reinforced Concrete Members without Shear Reinforcement", $A C I$ Structural Journal, Vol. 107, No. 5, 2010, pp. 516-525.

[8] STOFFEL P., Zur Beurteilung der Tragsicherheit bestehender Stahlbetonbauten. Doctoral thesis, ETHZ, Zurich, Switzerland, 2000, p. 185.

[9] MAKITA T., and BRÜHWILER, E., "Fatigue behaviour of bridge deck slab elements strengthened with reinforced UHPFRC", Proceedings, IABMAS: Bridge Maintenance, Safety and Management, Stresa, June 2012, pp. 1974-1980.

[10] SIA, SIA 269/2: 2011. Maintenance des structures porteuses - Structures en béton, Swiss society of engineers and architects, Zurich, 2011, p. 44.

[11] BRÜHWILER E., FEHLING E., BUNJE K., and PELKE E., "Design of an innovative composite road bridge combining reinforced concrete with Ultra-High Performance Fibre Reinforced Concrete",. Proceedings, IABSE Symposium: Improving Infrastructure Worldwide, Weimar, September 2007, pp. 80-81. 